\title{
Hypertension and Stroke
}

Can. J. Neurol. Sci. 2002; 29: 113-114

Hypertension is probably the most important cause of stroke, and controlling hypertension both before and after stroke is probably the most important measure in stroke prevention. Strokes due to high blood pressure are mainly lacunar infarctions due to occlusion of small resistance vessels by hyaline degeneration and fibrinoid necrosis, and intracerebral hemorrhages due to rupture of resistance vessels affected by those processes. ${ }^{1}$ In primary prevention, treatment of isolated systolic hypertension reduces stroke by nearly half, ${ }^{2}$ and reduced Alzheimer's dementia by half. ${ }^{3}$ Observations in a community blood pressure control study showed that the strokes that are eliminated by treatment of hypertension are almost entirely those due to hypertensive small vessel disease. ${ }^{4}$ In the North American Symptomatic Carotid Endarterectomy Trial, ${ }^{5}$ in which strenuous efforts were made to control blood pressure, only $0.4 \%$ of strokes were intracerebral hemorrhages. Recently, the PROGRESS trial ${ }^{6}$ has proven that treatment of hypertension significantly reduces recurrent stroke.

A transient rise in blood pressure commonly accompanies acute stroke. For many years a controversy has simmered regarding whether this should or should not be treated. Many authorities have strongly inveighed against any treatment of blood pressure in the acute stroke, based on concerns that the ischemic penumbra is dependent on flow that is now supported only by high blood pressures, because of loss of cerebral autoregulation. Fear of suddenly dropping the perfusion pressure too low with worsening of ischemia in the viable penumbra leads to fear of any treatment of hypertension.

On the other hand, I have argued for many years ${ }^{7}$ that there are some circumstances in acute stroke in which blood pressure must be treated, so the argument is not about whether hypertension should be treated in acute stroke, but how and when. Aortic dissection, pulmonary edema with concomitant myocardial infarction, hypertensive encephalopathy and worsening intracerebral hemorrhage with very high pressures likely represent circumstances in which the pressure must be treated. Furthermore, very high pressures probably aggravate edema and hemorrhage, so that control of severe hypertension may prevent worsening of the stroke itself., 7

With the advent of thrombolysis for acute stroke, treatment of high blood pressure in acute stroke has become more common. In this issue, Kanji et $\mathrm{al}^{9}$ show the appalling state of blood pressure management in acute stroke. Despite strong contraindication, the second commonest method of blood pressure lowering was with sublingual nifedipine, a treatment that should never be used because it cannot be controlled, and runs too high a risk of abrupt lowering of pressure to levels that are too low. ${ }^{10,11}$

Fortunately, this situation will soon come to a halt with the publication of the results of the ACCESS trial. ${ }^{12,13}$ In this study, "a beautiful hypothesis has been slain by ugly facts", as my teacher Henry Barnett is so fond of saying. After randomization of 342 patients to placebo vs candesartan for treatment of severe hypertension in acute stroke, the study was stopped early because of a significant excess of adverse outcomes in patients assigned to placebo. The composite outcome of death or vascular events occurred in $31(18.7 \%)$ of placebo patients, compared to $17(9.8 \%)$ of patients treated with candesartan.

It will now be possible to move on, as recommended by Kanji et al, to determining not whether hypertension should be treated in acute stroke, but when and how. Here I make my plea for studies of intravenous drugs that can be controlled, as opposed to regimens that once administered cannot be retracted, such as oral, sublingual or intramuscular drugs.

I also recommend that in the management of hypertension in acute stroke, more attention be paid to diagnosis. Severe hypertension is much more likely to be associated with an underlying cause, ${ }^{14}$ and patients with carotid stenosis and severe hypertension are much more likely to have renovascular hypertension. Surprisingly, adrenocortical hyperplasia is almost half as common in this population. ${ }^{15}$ The management of resistant hypertension is very much aided by knowing the physiological drivers of the hypertension in the individual patient: if the problem is due to activation of the reninangiotensin system, with secondary hyperaldosteronism, the appropriate treatment is very different from that of a patient with primary adrenocortical hypertension. ${ }^{16}$ It is very helpful, therefore, to draw a plasma renin and aldosterone before administering drugs such as beta-blockers, that prevent the determination of the physiology of the hypertension. I believe this should be done in the emergency room or as soon after admission as possible, in the setting of acute stroke and severe hypertension.

A new era of blood pressure treatment in stroke is upon us: it is now clear that hypertension must be treated after stroke, even in the acute stroke. Instead of wallowing in ignorance and being held back by authority, we need to determine the parameters of blood pressure treatment in acute stroke: at what levels should treatment be initiated, to what target should blood pressure be lowered, and by what means? New tools for measurement of cerebral blood flow, which are more widely available than PET scanning or functional MRI will make this possible. Dr. Ting Lee's method for regional cerebral blood flow measurement using deconvolution of contrast transit on a standard CTscan ${ }^{17,18}$ will undoubtedly play an important part in our learning how to treat hypertension in acute stroke, as will Dr. Philip Bath's consortium of investigators addressing this issue. ${ }^{19}$

\section{J. David Spence London, $O N$}




\section{REFERENCE}

1 Spence JD. Cerebral consequences of hypertension. In: Laragh JH, Brenner B, eds. Hypertension: Pathophysiology, Diagnosis, and Management. New York: Raven Press, 1995: 741-753.

2. SHEP Cooperative Research Group. Prevention of stroke by antihypertensive drug treatment in older persons with isolated systolic hypertension. Final results of the Systolic Hypertension in the Elderly Program (SHEP). JAMA1991;265:3255-3264.

3. Forette F, Seux M-L, Staessen J, Thij L, et al. Prevention of dementia in the Syst-Eur trial. Lancet 1998;352:1347-1351.

4. Spence JD. Antihypertensive drugs and prevention of atherosclerotic stroke. Stroke 1986;17:808-810.

5. Barnett HJ, Taylor DW, Eliasziw M, et al. Benefit of carotid endarterectomy in patients with symptomatic moderate or severe stenosis. North American Symptomatic Carotid Endarterectomy Trial Collaborators. N Engl J Med 1998 339(20):1415-1425.

6. PROGRESS Collaborative Group. Randomised trial of a perindopril-based blood pressure-lowering regimen among 6105 individuals with previous stroke or transient ischemic attack. Lancet 2001;358:1033-1041.

7. Spence JD, Del Maestro RF. Hypertension in acute ischemic strokes: Treat. Arch Neurol 1985;42:1000-1002.

8. Tietjen CS, Hurn PD, Ulatowski JA, Kirsch JR. Treatment modalities for hypertensive patients with intracranial pathology: options and risks. Crit Care Med 1996;24:311-322.

9. Kanji S, Corman C, Douen AG. Blood pressure management in acute stroke: comparison of current guidelines with prescribing patterns. Can J Neurol Sci 2002;2:125-131.

10. Spence JD, Zarnke KB. Stroke and Hypertension. In: Oparil S, Weber MA, eds. Hypertension: A Companion to Brenner and
Rector's The Kidney. Philadelphia: W.B. Saunders Company, 2000:266-286.

11. Spence JD, Paulson OB, Strandgaard S. Hypertension and Stroke. In: Messerli FH, ed. The ABCs of Antihypertensive Therapy. New York: Lippincott Williams \& Wilkins, 2000:279-296.

12. Schrader J, Röthemeyer M, Lüders S, Kollmann K. Hypertension and stroke - rationale behind the ACCESS trial. Basic Res Cardiol 1998;93(Suppl 2):69-78.

13. Schrader J, Lüders S, Kulchewski A, et al. [Acute Candesartan Cilexitil Evaluation in Stroke Survivors: a double-blind randomised comparison of candesartan cilexitil and placebo in the control of blood pressure after an acute stroke.] Hochdruck und Nierenkrankheit 2002; (abstract) in press

14. Spence JD. Stepped Care for Hypertension is dead but what will replace it? CMAJ 1989;140:1133-1136.

15. Spence JD. Management of resistant hypertension in patients with carotid stenosis: high prevalence of renovascular hypertension. Cerebrovasc Dis 2000;10:249-254.

16. Spence JD. Physiologic tailoring of therapy for resistant hypertension: 20 years experience with stimulated renin profiling. Am J Hypertens 1999;12:1077-1083.

17. Eastwood JD, Provenzale JM, Hurwitz LM, Lee TY. Practical injection-rate CT perfusion imaging: deconvolution-derived hemodynamics in a case of stroke. Neuroradiology 2001; 43(3):223-226.

18. Nabavi DG, Cenic A, Craen RA, et al. CT assessment of cerebral perfusion: experimental validation and initial clinical experience. Radiology 1999;213(1):141-149.

19. Bath P, Boysen G, Donnan G, et al. Hypertension in acute stroke: what to do? Stroke 2001; 32(7):1697-1698. 